\title{
Factors Affecting Employees' Turn over in the Hotel Industry a Case of Bahir Dar City
}

\author{
Temesgen Ayenew Birhan \\ Department of Accounting and Finance, College of Business and Economics, Bahir Dar University
}

\begin{abstract}
Employee turnover is that the major problems for business employing staff and it are not uncommon in hotel industry. Human Resources Management contains a vital role to play in managing the organization resources and the way employees are treated within the organization. Employees are a crucial asset to each company, business and organization. Because, the success of every company or business is entirely dependent on the effectiveness of its workforce. The first objective of this study is determining factors which influencing employee's turnover in hotel industry. To attain this objective the researcher collects data from respondents through structured questionnaire. The survey prepared in 5 point likert type. Structural equation model was employed for data analysis and Amos graphics taken as statistical tools. Finally the researcher reach the finding of salary and related benefit, working environment and management practices are responsible factors for employee's turnover in Bahir Dar hotel industry.
\end{abstract}

Keywords: Employee turnover, structural equation model, Amos graphics

DOI: $10.7176 /$ RJFA/13-3-02

Publication date: February $28^{\text {th }} 2022$

\section{Introduction}

Employee turnover is serious problem in many businesses. Research evidenced that a high employee turnover rate has negative impact on business sustainability and operation by increasing cost of hiring and training new employees, reducing productivity of employees and missing sales (Faldetta, Fasone, \& Provenzano, 2013). In hospitality industry, employees are important part of customer experience. The hospitality industry is more negatively affected by employee turnover because the employees are the main 'tools' to create and render service from the hospitality organization to the customers. From this point of view, high employee turnover level is a serious problem in the hotel industry (Faldetta, Fasone, \& Provenzano, 2013).

Human resources management is a very crucial element in running a health organization; Organizations possess different kinds of resources to achieve their objectives. These resources can be money, materials, machines and human beings. Of all these resources only human being (workers) have the ability to develop and improve their abilities and skills. It is also very obvious that the human power belonging to an organization controls the other resources and hence, they can be considered as the most important resource (Armstrong, 2012).

Human Resources Management incorporates a vital role to play in managing the organization resources and the way employees are treated within the organization. Employees are a crucial asset to each company, business and organization. Because, the success of every company or business is entirely dependent on the effectiveness of its workforce. A business may invest lots of resources into its core operations and activities, but without a highly effective human resource, success within the future can't be achieved (Tom \& Huckman, 2008). According to (Tracey \& Hinkin, 2008), productivity is incredibly important issue or a target for each industry or organization to a chive its objective. There are several challenges on which productivity of a corporation mostly depends upon. Employee's turnover is one in all them which are considered to be one among the challenging issues in business nowadays.

\section{Statement of the problem and Research Gap}

One in every of the foremost challenging issues faced by the hospitality organizations today is to manage the changing employment relationship. Being in customer service business, hospitality industry capitalizes heavily on its human resources to attain its competitive advantage. Hospitality industry may be a high customer service oriented business where interaction between employees and customers determine the competitive advantages and success of the business (Chand \& Katou, 2007).

The hospitality industry may be a company that usually experience ratio caused by internal problem that occurred at the corporate, internal problems it also causes a high rate of ratio. Turnover may disrupt the company's performance. The hospitality sector is oriented to customer satisfaction; therefore the hospitality industry should have qualified human resources to supply excellent service to customer. The success of the hospitality industry will be seen from the customer satisfaction through the service provide by the hotel. High levels of intention turnover has become a significant problem for companies, even some companies experiencing frustration when he learned that the recruitment process has secured the staff finally clad to be futile because the staff who are recruited and work his company has chosen employment in another company (Hinkin \& Tracey, 2000). 
Employee turnover is related with the productivity of an organization. It can hamper the overall productivity of an organization and is often a symptom of other difficulties. It is very important to manage turnover for both government and non-government sectors. In government sectors, although some benefits are given to the employees regularly do not satisfy them sufficiently (Mobley, 1977). In contrast to this, in private sector salaries and benefits are high but, the security of job is very low. Due to this reason employee turnover rate in private sector is higher than in public ones. The rate of employee turnover is varies from hotel to hotel and region to region. The highest turnover rate is occurring when unemployment rate is low and easy for people to get alternative jobs.

Employee turnover is incredibly detrimental to the corporate and therefore the overall economy. Ratio has different cost to the corporate like, Direct Costs and Indirect Costs. The direct costs related to the loss of your time and money to recruit, hire and train employees. The indirect cost is that the decline in production and services because the corporate has not found a replacement for the worker to perform work that had previously been left behind by employees who resign or hire new employees who don't have experience and may incline training (Hinkin \& Tracey, 2000). Recruit, select and train new employees often spend lots of cash, because the upper the ratio, the upper the expenditure will occur (Lussier, 2005).One of the private service sectors that are highly important and developing during a prominent way within the region may be a hospitality industry where there are stars, standardized, medium and lower hotels which directly help for the event of tourism and investment. Though, this sector is crucial for the event and building for the positive image of the region (Morrell et al., 2001). The most focus of the hospitality industry is to supply excellent service and good experience to the purchasers and also the quality service is delivered by the staff (Crick \& Spencer, 2011). Hospitality may be a competitive sector during which the staff have new challenges on a daily basis and even have the pressure to compete with the co-workers to urge better position. As it's a good field, there might be numerous issues during this industry which may be discussed but the researcher has chosen this subject because the industry is facing enormous challenge in retaining the standard staff and maintains the worker turnover.

\section{Research objectives}

The major objective of this study was determining factors which influencing employee's turnover in hotel industry in Bahir city. The specific objectives provided as follows:

* To examine the impact of salary and related benefit on employee turnover in hotel industry.

\# To examine the influence of working environment on employee turnover in hotel industry.

\# To examine the effect of career development on employee turnover in hotel industry

* To identify the impact of Recruitment and Selection process on employee turnover in hotel industry.

* To examine the impact of training experience on employee turnover in hotel industry.

* To explore the effect of management practices on employee turnover in hotel industry.

\section{Research Hypothesis}

The researcher established the following hypothesis after reviewing various theoretical and empirical related literatures for practices of employee turnover and identifiable factors contribute for employee turnover. All hypotheses were test by structural equation model and well explained at the end of this article.

H1: Salary and related benefit has positive and significant effect on employee turnover in hotel industry

$\boldsymbol{H}$ H2: Working environment influence positively and significantly the employee turnover.

> H3: Career development has positive and significant effect on employee turnover in hotel industry.

H4: Recruitment and selection process has positive and significant impact on employee turnover in hotel industry.

H5: Training experience has positive and significant impact on employee turnover in hotel industry

H6: A Management practice has positive and significant impact on employee turnover in hotel industry.

\section{Conceptual framework}

The following conceptual framework presents both dependent and independent variable with their ways of measurement. This framework developed by referring theoretical and empirical literature review in broad concept. Those variables are recruitment and selection, training, career growth opportunities, salary and benefit, management practice and working environment. The conceptual frame developed by referring theoretical and empirical literature. 


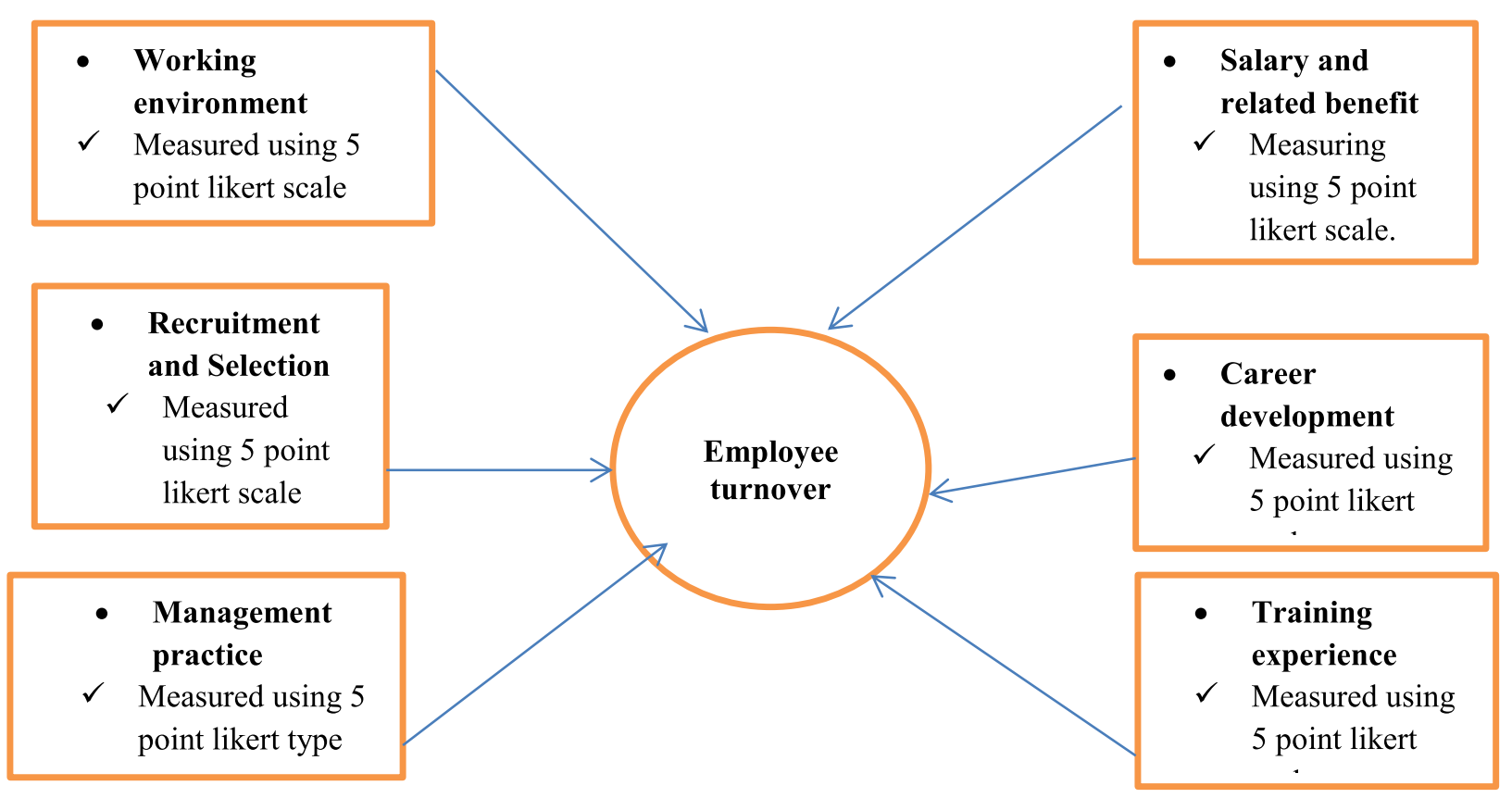

\section{Research methodology}

This subsection provides some brief description about research approach, identification of target population, sampling and ways of data analysis

Research approaches: The inquiry paradigm utilized in research is usually influenced by researcher ontological and epistemological beliefs. These beliefs represent how the researcher views and seeks to know the globe. The two extremely contradicting paradigms are positivism and constructivism. Thus, positivist researchers normally adopt quantitative methods and constructivist researchers adopt qualitative methods. The opposite paradigm is combination of positivism and constructivism (that is mixed method).

Target Population and sampling: The target population of this study is composed of employees from each hotel in Bahir Dar city. 150 employees have taken as sample of from total population of employees hires in hotel industry. Stratified sampling techniques used in this research.

Method of Data Collection: Data collected from secondary source to establish literature and getting knowhow about the research and general process of doing best research. Not only secondary data, primary data also used to gather information and measured the perception of respondents. To collect primary data survey is usual and best techniques. Under this research the survey prepared in five point likert type.

Method of Data Analysis: Under this study structural equation model used for data analysis. The best Structural equation modeling (SEM) is a statistical tool for analyzing a structural theory that has an impact on a phenomenon using a confirmatory (i.e. hypothesis-testing) approach. The well-known terms are observed variables and latent variable. Observed variables also called indicator variables or manifest variables. Latent variables also denoted unobserved variables or factors. The latent variables can't be measured directly. The latent variable must be defined in terms of observed variables to represent it. During this research six independent variables are observed variables and ratio is latent variable.

\section{Measurement of Reliability and Validity}

Reliability-is the degree to which the measure of a construct is consistent or dependable. The reliability of a measure indicates the extent to which it is without bias (error free) and hence ensures consistent measurement across time and across the various items in the instrument. This refers to the repeatability of a measure, i.e., the degree of closeness between between repeated repeated measurement measurements of the same value. In other words, the reliability of measures is an indication of the stability and consistency with which the instrument measures the concept and helps to assess the "goodness" of a measure. 


\begin{tabular}{|l|l|l|l|l|}
\hline Variables & Symbol & No. of items & Value of alpha & Status \\
\hline Salary and relates benefit & SRB & 5 & 0.87 & Great \\
\hline Working environment & WE & 5 & 0.76 & Good \\
\hline Career development & CD & 5 & 0.78 & Good \\
\hline Selection and recruitment & SR & 5 & 0.65 & Fair \\
\hline Training experience & TE & 5 & 0.75 & Good \\
\hline Management practice & MP & 5 & 0.88 & Great \\
\hline Employee turnover & ET & 5 & 0.82 & Great \\
\hline
\end{tabular}

Source: SPSS output, 2021

\section{Testing of data validity}

Validity- refers to the extent to which a measure adequately represents the underlying construct that it is supposed to measure. It can be assessed using theoretical approach (Translational Validity) or empirical approaches (Construct Validity), and should ideally be measured using both approaches. Convergent validity refers to the closeness with which a measure relates to (or converges on) the construct that it is purported to measure, Discriminant validity refers to the degree to which a measure does not measure (or discriminates from) other constructs that it is not supposed to measure.

\begin{tabular}{|c|l|l|l|l|l|l|}
\hline $\begin{array}{c}\text { Convergent } \\
\text { validity }\end{array}$ & SRB & WE & CD & SR & TE & MP \\
\hline $\mathrm{AVE}=\sum\left(\mathrm{Xi}^{2} / \mathrm{N}\right)$ & 0.53 & 0.75 & $0.66 \quad 0.59$ & 0.77 & 0.68 \\
\hline Validity & \multicolumn{6}{|c|}{ Established } \\
\hline
\end{tabular}

$\mathrm{Xi} \rightarrow$ The value of regression weight under each construct. $\mathrm{N} \rightarrow$ Number of observed variables under each construct.

\begin{tabular}{|c|c|c|c|c|}
\hline Discriminant validity & $\begin{array}{l}\text { Factor } \\
\text { correlation(r) }\end{array}$ & $\begin{array}{l}\text { Correlation } \\
\text { Squared }\left(\mathrm{r}^{2}\right)\end{array}$ & $\mathrm{AVE}>\mathrm{r}^{2}$ & Discriminant validity \\
\hline $\mathrm{SRB} \leftrightarrow \mathrm{WE}$ & -0.020 & 0.0004 & \multirow{5}{*}{0.63} & \multirow{5}{*}{ Established } \\
\hline $\mathrm{SRB} \leftrightarrow \mathrm{CD}$ & -0.053 & 0.003 & & \\
\hline $\mathrm{SRB} \leftrightarrow \mathrm{SR}$ & -0.085 & 0.007 & & \\
\hline $\mathrm{SRB} \leftrightarrow \mathrm{TE}$ & 0.056 & 0.003 & & \\
\hline $\mathrm{SRB} \leftrightarrow \mathrm{MP}$ & 0.011 & 0.0001 & & \\
\hline $\mathrm{WE} \leftrightarrow \mathrm{CD}$ & 0.130 & 0.017 & \multirow{5}{*}{0.65} & \multirow{5}{*}{ Established } \\
\hline $\mathrm{WE} \leftrightarrow \mathrm{SR}$ & 0.149 & 0.022 & & \\
\hline $\mathrm{WE} \leftrightarrow \mathrm{TE}$ & -0.282 & 0.08 & & \\
\hline $\mathrm{WE} \leftrightarrow \mathrm{MP}$ & 0.163 & 0.023 & & \\
\hline $\mathrm{CD} \leftrightarrow \mathrm{SR}$ & 0.178 & 0.032 & & \\
\hline $\mathrm{CD} \leftrightarrow \mathrm{TE}$ & 0.296 & 0.0877 & \multirow{4}{*}{0.69} & \multirow{4}{*}{ Established } \\
\hline $\mathrm{CD} \mathrm{MP}$ & 0.070 & 0.005 & & \\
\hline $\mathrm{SR} \leftrightarrow \mathrm{TE}$ & 0.199 & 0.04 & & \\
\hline $\mathrm{SR} \leftrightarrow \mathrm{MP}$ & 0.013 & 0.0002 & & \\
\hline $\mathrm{TE} \leftrightarrow \mathrm{MP}$ & -0.045 & 0.009 & 0.60 & Established \\
\hline
\end{tabular}

\section{Structural Model and hypotheses testing}

After testing the validity of CFA, it is the time to confirm the research hypotheses by testing the structural model which will empirically identify the relations between the factors. First, there is a need to check the model fit and minimum of four indices should be considered in this context (Hair et al., 2010). This study employed the same indices used when it checked CFA model fit. Therefore, as presented in the following table, acceptable value of RMSEA was found indicating good fit associated with PCLOSE less than 0.05 , in addition, CFI, IFI, and TLI were very close to 0.9 which is also accepted according to the suggested value of Hu and Bentler (1999). Chi-squared was also in the range $>1$ and $<5$ associated with significant $p$-value.

\begin{tabular}{|l|l|l|}
\hline Indices & Default model & Suggested criteria \\
\hline RMSEA & 0.074 & $<0.08$ \\
PCLOSE & 0.000 & $<0.05$ \\
\hline$X^{2} /$ df & 2.99 & Between 1 and 5 \\
$\mathrm{P}$ value & 0.000 & $<=0.001$ \\
\hline CFI & 0.875 & Close to 0.9 \\
\hline IFI & 0.922 & Close to 0.9 \\
\hline TLI & 0.894 & Close 0.9 \\
\hline
\end{tabular}




\section{Goodness of fit for Structural Model}

Proceeding to the next step of hypotheses testing, this study considered analyzing the path significant of each relationship, where it examined the standardized estimate (S.E), critical ratios (C.R) and p-value for each proposed relationship. A relationship is considered as significant if a $t$-value $>1.96$ and a $p$-value $\leq .05$ ). Therefore, in order to obtain $t$-value, the regression weight estimate should be divided by standard error (S.E). Therefore, the regression weight estimates of the eight hypotheses in this study are presented in the following table and all the results indicate that all casual paths for these eight hypotheses are significant with the $t$-values above 1.96 and the $\mathrm{p}$-value is $\leq .05$.

10. Hypothesis Testing using Structural Model

\begin{tabular}{|l|l|l|l|l|l|l|l|}
\hline Hypotheses & Variables & Estimates & S.E. & C.R & P & Status & Outcome \\
\hline H1 & ET --SRB & -0.128 & 0.065 & -1.969 & 0.030 & Positive and significant & Accept \\
\hline H2 & ET--WE & 0.139 & 0.064 & 2.194 & 0.028 & Positive and significant & Accept \\
\hline H3 & ET--CD & 0.16 & 0.072 & 2.212 & 0.22 & Positive and insignificant & Reject \\
\hline H4 & ET--SR & 0.005 & 0.048 & 0.113 & 0.910 & Positive and insignificant & Reject \\
\hline H5 & ET-TE & -0.23 & 0.098 & -2.335 & 0.38 & Positive and insignificant & Reject \\
\hline H6 & ET--MP & 0.344 & 0.103 & 3.339 & 0.000 & Positive and significant & Accept \\
\hline
\end{tabular}

\section{Conclusion}

\section{Salary and benefits}

Inequity in pay structures or low pay and absence of advantages is great causes of dissatisfaction and might drive some employees to quit. Again, a brand new worker may wonder why the person next to him is receiving the next wage for what's appeared to be the identical work. Lack of skill and lack of coaching make the staff at hospitality industry have an occasional income compared with another industry. Educational programmes and professional development will help to ensure the quality of services while also increasing productivity, resulting in higher earnings for hospitality workers. Salary difficulties were the most common cause for employees in the hotel business to resign. Employees are less likely to resign from a company if the promotion and compensation offered by the company are competitive. Promotion and compensation issues are seen as extremely crucial issues for employees (Bloome, 2010). Employee salary and related benefits have a large and beneficial effect on turnover, as indicated in the data analysis output.

\section{Working Environment}

Working Environment is the place that most people choose to work at. Different hazards occur at any work environment in terms of noise pollution, radiation from computer, inappropriate lighting system. It is also a physical and psycho-social work environment in which physical work environment includes welfare provisions, working condition and safety, while psycho-social work environment includes interpersonal relation, reward system, trust and support (srivastava, 2008).

\section{Career development}

One of the reasons for this is that there is no clear career path in the hotel business. Aside with the lack of a clear career path, another reason is the unemployed challenge, which is focused on customers and pays less. They're looking for a demanding work that will allow them to advance their careers while also paying them fairly. Its manager's commitment to resolving the issue gives the company the opportunity to reduce the number of employees who planned to resign. As social responsibility measures, development programmes such as career progression training programmes, capacity building programmes, and training in specialized areas are essentially non-existent. It's self-evident that hotel corporations should do a better job of hiring high-quality staff and better training those (Bagri et al, 2010).

\section{Recruitment and Selection}

The process of developing a pool of qualified candidates for a certain post is known as recruitment. It's also a method for attracting potential employees and inspiring and motivating them to apply for positions in a company. As a result, recruiting is the process of attracting people at the right time, in sufficient numbers, and with the right qualifications, and motivating them to apply for jobs. According to Mardianto (2014), the recruitment process is the process of obtaining people who meet the organization's requirements using available resources. The recruitment process begins when a corporation recognizes a vacant job vacated by an employee, locates a labourer, and approaches the manager.

\section{Training Experience}

Training is a method or strategy used by the hospitality sector to reduce employee turnover. Besides minimizing the turnover employee, the training could raise the standard of the worker. The hospitality business pays a small amount of attention to training. According to Davidson et al. (2011), coaching and service quality are two of the most important issues for the long term, just as they were in the past. The need of examining the wants of what's 
needed to be fulfilled on a regular basis is critical in the hospitality sector. For a variety of reasons, formal and informal training played an important role, including the industry's global expansion, the need to reduce worker turnover, and the need to increase knowledge and career routes., increase the legal requirements and therefore the important is for increasing the standard of service that provide to customers. The absence of an educational program may cause workers to fall behind in their level of performance and feel that their abilities are lacking.

Management practice

According to Robbins (1998) supervision is that the guidance that's offered by the one who has higher position like supervisors and managers. Employees view supervision as a part to meet their needs that's associated with their job. If supervisors are fair to everyone and maintain an honest relationship with their subordinates, employees' job satisfaction will increase.

\section{Bibliography}

Armstrong, M. (2012). A handbook of human resorce management practice. London: kogan press.

Bloome. (2010). Work family conflict as cause fortrunover intenion . Tourisim and hosipitality reerach .

Bolch, A. (2001). Benchmarking the quality of hotel service. Managerial perspective International journal of Quality and Reliability management, 582-597.

Crick, A. p., \& Spencer, A. (2011). hospitality of quality: New direction and chalenges. international journal of contemporarary hospitality management, 463-478.

Faldetta, G., Fasone, V., \& Provenzano, C. (2013). Turnover in hospitality industry. pasos: Revita De Tunismo Y patrimonio Cultural.

Hinkin, \& Tracey. (2000). The cost of turnover.putting aprice on the learning curve. cornel hotel and restorant administration Quarterly, 14-21.

Lussier, N. R. (2005). Human relation in Organazational Application and skill building . NEW York: Mc Graw Hill.

Mobley, W. H. (1977). Intermidiate linkage in the relationship between job satisfaction and employee turnover. Journal applied psychology, 237-240.

Tom, \& Huckman. (2008). employees' organizational comitment and thier perception of supervisors' relation oriented and task oriented leadership behaviors . verginia: faculity of verginia polytechnique institute and state university.

Tracey, J., \& Hinkin, T. (2008). Contexual factors and cost profiles associated with employee turnover. Cornell Hospitality Quarterly, 12-27. 